\title{
Ketogenic treatment reduces the percentage of a LHON heteroplasmic mutation and increases mtDNA amount of a LHON homoplasmic mutation
}

\author{
Sonia Emperador ${ }^{1,2,3 \dagger}$, Ester López-Gallardo ${ }^{1,2,3 \dagger}$, Carmen Hernández-Ainsa ${ }^{1,2}$, Mouna Habbane ${ }^{1}$, Julio Montoya ${ }^{1,2,3}$,
} M. Pilar Bayona-Bafaluy ${ }^{1,2,3^{*}}$ and Eduardo Ruiz-Pesini ${ }^{1,2,3,4^{*}}$ (D)

\begin{abstract}
Background: The vision loss in Leber hereditary optic neuropathy patients is due to mitochondrial DNA mutations. No treatment has shown a clear-cut benefit on a clinically meaningful end-point. However, clinical evidences suggest two therapeutic approaches: the reduction of the mutation load in heteroplasmic patients or the elevation of mitochondrial DNA amount in homoplasmic patients.
\end{abstract}

Results: Here we show that ketogenic treatment, in cybrid cell lines, reduces the percentage of the m.13094 T > C heteroplasmic mutation and also increases the mitochondrial DNA levels of the m.11778G > A mitochondrial genotype.

Conclusions: These results suggest that ketogenic diet could be a therapeutic strategy for Leber hereditary optic neuropathy.

Keywords: Mitochondrial DNA, Leber hereditary optic neuropathy, Ketogenic diet

\section{Background}

Leber hereditary optic neuropathy (LHON) is a kind of blindness due to retinal ganglion cells (RGC) loss provoked by pathologic mutations in the mitochondrial DNA (mtDNA), mainly in genes for respiratory complex I (CI) subunits. Three of these mutations, m.3460G $>A$, m.11778G $>\mathrm{A}$ and m.14484 $\mathrm{T}>\mathrm{C}$, account for most of LHON patients. The remaining cases are caused by a number of very rare mutations, such as m.13094 $\mathrm{T}>\mathrm{C}$ [1].

The existence of mutant and wild-type mtDNA, known as heteroplasmy, is found in $10-15 \%$ of individuals [2]. Blood mutation load in these heteroplasmic individuals is directly related to the frequency of vision loss [3]. Heteroplasmy is frequent in patients who recover their vision. The lower the percentage of pathological mutation, the higher the probability of spontaneous recovery [4]. Interestingly, it was previously

\footnotetext{
* Correspondence: pbayona@unizar.es; eduruiz@unizar.es

†Sonia Emperador and Ester López-Gallardo contributed equally to this work. ${ }^{1}$ Departamento de Bioquímica, Biología Molecular y Celular, Universidad de Zaragoza, C/ Miguel Servet, 177. 50013, Zaragoza, Spain

Full list of author information is available at the end of the article
}

reported that osteosarcoma 143 cybrids with an heteroplasmic $1.9 \mathrm{~kb} \mathrm{mtDNA}$ deletion grown 5 days in a medium with no glucose but with acetoacetate (AA), $\beta$ hydroxybutyrate $(\mathrm{BHB})$ or both $(\mathrm{AA}+\mathrm{BHB})$ suffered a slight decrease $(7-20 \%)$ in proportion of deleted mtDNA [5]. The result of this ketogenic treatment suggested a possibility to decrease the LHON pathologic point mutation load in heteroplasmic patients.

Most LHON individuals are homoplasmic, i.e. they only have mutant mtDNA, and mutation load cannot be decreased. However, not all individuals harboring a LHON homoplasmic mutation suffer the disease. In mutant homoplasmic individuals, mtDNA levels were found to be lower in patients than in healthy carriers [6]. Moreover, risk factors for LHON, whether genetic, such as mtDNA haplogroup J; physiological, such as male gender; pharmacological, for example antiretroviral therapy; or environmental, such as smoking, have also been associated with lesser mtDNA amount [7]. Remarkably, it has also been shown that neuroblastoma SH-SY5Y cybrids with an almost homoplasmic (98.6\%) pathologic

C The Author(s). 2019 Open Access This article is distributed under the terms of the Creative Commons Attribution 4.0 International License (http://creativecommons.org/licenses/by/4.0/), which permits unrestricted use, distribution, and 
point mutation $(\mathrm{m} .3243 \mathrm{~A}>\mathrm{G})$ showed an increase in the mtDNA copy number, with no change in the mutation load, when cultured for 28 days in a medium with ketone bodies and low glucose [8]. This result suggested that ketogenic diet (KD), a high fat and low carbohydrate diet, by increasing mtDNA levels, might also be a therapeutic strategy for LHON homoplasmic individuals.

Currently, there are no level I clinical trial data supporting the use of any medication in LHON. Education and a reduction of all the likely risk factors are the bedrock of management in LHON [9]. To explore the use of $\mathrm{KD}$ as a potential therapy for LHON patients, we simulated this approach in heteroplasmic and homoplasmic cybrids, trying to decrease LHON mutation load or increasing the mtDNA copy number.

\section{Results}

Reducing the heteroplasmic mutation percentage

In a previous work, we described a LHON patient with the m.13094 T > C mtDNA transition and confirmed its pathogenicity using cybrids [1]. These cybrids (O13094) harbored a $50.3 \%$ of the mutant allele. Here, we observed a significant decrease in the proportion of m.13094 T > C transition when cybrids were grown with no glucose in the presence of AA (up to 27.7\%) or BHB (up to $30.7 \%$ ) (Fig. 1a, b). Interestingly, AA + BHB further reduced the mutation load (up to 16.7\%).

Moreover, when cybrids with a $20 \%$ mutation load were cultured for additional 6 or 12 days in a medium with no glucose but with AA + BHB, they practically lost the m.13094 $\mathrm{T}>\mathrm{C}$ transition (Fig. 1c). A different type of


Fig. 1 Effect of ketogenic treatment on mtDNA mutation percentage and copy number. a Percentage of m.13094 T>C transition. Gel showing PCR-RFLP results for cybrids with the m.13094 T > C mutation. M, molecular weight marker; Am, amplicon; C-, negative control; G, 5.5 mM glucose grown mutant cybrid; A, $5 \mathrm{mM}$ acetoacetate-treated mutant cybrid; B, 5. mM $\beta$-hydroxybutyrate-treated mutant cybrid; $A B, 5$ mM acetoacetate + $5 \mathrm{mM} \beta$-hydroxybutyrate-treated mutant cybrid. Heteroplasmy produces two new bands ( $218+188$ base pairs). b Graph showing percentage of m.13094 T > C mutation in cybrids. These percentages were obtained from the Fig. 1a gel. Statistically significant differences are indicated by * (vs G) or \# (vs A or B). c Percentage of m.13094 T > C transition. Gel showing PCR-RFLP results for m.13094 T > C mutation, in fibroblast and cybrids, after additional ketogenic treatment. G6 and G12, cybrids with 20\% mutation load grown in G medium for additional 6 and 12 days, respectively. AB6 and AB12, cybrids with 20\% mutation load grown in AB medium for additional 6 and 12 days, respectively. d ATP levels in cybrids with different m.13094 T > C mutation load. Dashed line represents ATP levels in the Owth control cybrid. Statistically significant differences are indicated by * (vs Owth), \& (vs O13094, 0\%), or \# (vs 013094, 20\%). e mtDNA levels in wild-type and LHON mutant cybrids. mtDNA amount in each untreated cybrid is considered 100\% (dashed line). Statistically significant differences are indicated by * (vs untreated cybrid). 
cell, patient's fibroblasts (70.5\%) mutation load), also showed a reduction in the mutation load when grown in $\mathrm{AA}+\mathrm{BHB}$ (up to 40\%) (Fig. 1c).

To study the bioenergetic effect of the reduction in the mutation percentage, we determined the ATP levels. These levels were significantly lower in cybrids with a $50 \%$ of pathological mutation than in those with a $20 \%$ (Fig. 1d). ATP amount in both cybrids was significantly lower than that in their isogenic control, with the same mtDNA genotype except for the pathological mutation. ATP concentration was the same in the isogenic cybrid and a control cybrid from another haplogroup and with no pathological mutation. Thus, the decrease in the cybrid mutation load was associated with an increase in ATP amount to reach normal levels (Fig. 1d).

\section{Increasing the homoplasmic mutant mtDNA levels}

We had previously observed an inverse relationship between the percentage of $\mathrm{m} .13094 \mathrm{~T}>\mathrm{C}$ mutation and the mtDNA copy number [1]. The ketogenic treatment (no glucose and AA + BHB) decreased the mutation percentage but also increased mtDNA amount.

To explore the effect of ketogenic treatment on mtDNA levels of LHON homoplasmic mutant cells, we analyzed five osteosarcoma 143B cybrid cell lines: two free of pathological mutations (Owth and Owtj) and three carrying the most common LHON mutations (O3460J, O11778J and O14484J). We had previously confirmed that all three mutant cybrids are homoplasmic, and along with Owtj, share the same nuclear genetic background and belong to the same mtDNA genetic background, haplogroup J [10]. Here, we first analyzed 16 short tandem repeats (STR) and confirmed that Owth also shares the same nuclear genetic background than the previous cybrids, but it belongs to the most common European mtDNA genetic background, haplogroup $\mathrm{H}$ (GenBank HM103354.1).

Next, we determined their mtDNA levels after 7 days growing in no glucose, $\mathrm{AA}+\mathrm{BHB}$ containing medium. Treated cybrids tent to have higher mtDNA levels (Fig. 1e). Moreover, treated O11778J cybrids showed significantly higher mtDNA levels (Fig. 1e). In osteosarcoma 143B cybrids, we previously described that mtDNA amount determines OXPHOS capacity [11].

\section{Discussion}

The O13094 heteroplasmic cybrid, when grown in no glucose medium with AA and/or BHB, decreases its mutation load. A similar observation had been previously published [5]. The reduction in the percentage of m.13094 T > C transition may be due to a selection of healthier mitochondria or cells. In fact, it had been described a significant negative correlation between the percentage of $\mathrm{m} \cdot 13094 \mathrm{~T}>\mathrm{C}$ mutation and the CI activity [12], which would explain our observation of an increase in ATP concentration when the mutation level is reduced. The catabolism of $\mathrm{AA}$ and $\mathrm{BHB}$ requires mitochondrial tricarboxylic acid cycle and oxidative phosphorylation (OXPHOS). Moreover, by reducing glucose concentration and limiting glycolysis, cells become more dependent on mitochondria to obtain energy. In fact, apparently homoplasmic SH-SY5Y cybrids reduced the m.3243A > G mutation load to $90 \%$ when its growth medium was shifted from high $(25 \mathrm{mM})$ to low $(2.75$ $\mathrm{mM}$ ) glucose [13]. Thus, the growing medium that we use probably selects for less mutated mitochondria or cells. It has been reported that, beside their metabolic effects, ketone bodies have also other properties, such as gene expression regulation [14]. These other properties could be responsible for the larger decrease in mtDNA mutation load when AA + BHB, instead AA or BHB, are used.

The homoplasmic cybrid O11778J significantly increases its mtDNA levels when growth in no glucose medium with AA + BHB. Although no significant, the remaining cybrids show a similar tendency. As previously commented, glucose deprivation requires a cellular energetic shift from glycolysis to OXPHOS. Cells can also grow on galactose medium but must derive much of their energy from OXPHOS [15]. In fact, aerobic oxidation of glutamine provides most of the energy when galactose is the carbohydrate in the growing medium [16]. Thus, it was reported that human cervical cancer HeLa and osteosarcoma U2OS cells increased respiration when glucose $25 \mathrm{mM}$ was substituted by glucosefree/galactose $10 \mathrm{mM}$ growing media $[17,18]$. The higher oxygen consumption in these cells was accompanied by densely packed mitochondrial cristae, increased supercomplex activities and levels and enrichment in respiratory complex proteins $[17,18]$. In HeLa cells growing in galactose medium, a nonsignificant increase in mtDNA levels was observed [17]. Control and LHON osteosarcoma 143B cybrids showed an increase in mtDNA amount and MT-CO1 and MTND5 mRNA levels after incubation in glucose-free/galactose $5 \mathrm{mM}$ medium [19]. The reduction of glucose concentration, from 30 to $5.5 \mathrm{mM}$, also increased oxygen consumption and mtDNA copy number in HepG2 cells [20]. Human neuroblastoma SH-SY5Y cybrids showed increased oxygen consumption, CI activity, p.MT-CO2 subunit amount and mtDNA levels when glucose concentration was decreased from 25 to $2.75 \mathrm{mM}$ [21]. Reduction in glucose concentration from 25 to $1 \mathrm{mM}$ increased oxygen consumption in U2OS cells [18]. Human hepatocellular carcinoma HepG2 cells growing in absence of glucose showed an increase in CIV activity, mtDNA-encoded proteins and mRNAs and mtDNA amount versus cells growing at glucose $25 \mathrm{mM}$ [22]. Additionally, it has been shown that KD induces 
mitochondrial biogenesis [23-28], frequently accompanied by increased mtDNA amount $[8,29-31]$. It is important to remark that we have compared mtDNA levels in cybrids grown in medium with AA + BHB but no glucose, with those grown in glucose $5.5 \mathrm{mM}$. Therefore, the elevation in mtDNA levels when glucose concentration is reduced from $25 \mathrm{mM}$ to $5.5 \mathrm{mM}$ or no glucose (but with $\mathrm{AA}+\mathrm{BHB}$ ) probably masked a lower effect of $\mathrm{AA}+\mathrm{BHB}$ on mtDNA amount. Thus, mitochondrial biogenesis and OXPHOS function, and their surrogate marker mtDNA copy number, increase with glucose deprivation, both in wild-type and mutant cells.

In mouse, a positive and significant correlation was found between mtDNA levels and uncoupled oxygen consumption in Lewis lung carcinoma LL/2-m21 cybrids [32]. In human, we had found that mtDNA copy number was lower in Western Europe haplogroup $J$ than $\mathrm{H}$ osteosarcoma 143B cybrids [11]. These lower mtDNA levels were accompanied by lower mitochondrial RNA amount, significant decrease in mitochondrial protein synthesis, reduction in mitochondrial inner membrane potential and ATP levels. Moreover, mtDNA levels significantly and positively correlated with mitochondrial RNA levels, mitochondrial protein synthesis and mitochondrial inner membrane potential [11]. It was also found that mtDNA copy number was higher in East Asian macrohaplogroup $\mathrm{M}$ than $\mathrm{N}$ osteosarcoma 143B cybrids [33]. These higher mtDNA levels were accompanied by higher mitochondrial RNA amount, significant increases in respiratory complex III levels, rise in mitochondrial oxygen consumption and in $\mathrm{NAD}^{+} / \mathrm{NADH}$ ratio [33]. It was also reported that, after estradiol treatment, control and LHON (m.3460G > A, m.11778G > A and m.14484 $\mathrm{T}>\mathrm{C}$ ) mutant osteosarcoma 143B cybrids increased mtDNA copy number, oxygen consumption and mitochondrial inner membrane potential [19]. Moreover, estradiol-treated control and m.3460G $>$ A cybrids increased MT-CO1 and MT-ND5 mRNA levels and p.MTND6 polypeptide amount [19]. Estradiol-treated control and m.11778G > A cybrids increased total ATP cellular content [19]. All these results confirm that mtDNA amount largely determines the OXPHOS function and could explain why risk factors for LHON have been associated with lesser mtDNA amount [7], and why higher mtDNA levels protect against LHON mutations, as reported in healthy homoplasmic LHON mutation carriers $[6,34]$. Perhaps, mutant proteins are partially actives or, maybe, they can be found in an active/inactive dynamic equilibrium. In both cases, higher mutant protein amount would imply higher activity.

KD was used in children with epilepsy and OXPHOS defects, most of them in CI, the one affected in LHON patients. This diet was a safe and effective therapy for these patients [35]. KD was applied to a young girl suffering Alpers-Huttenlocher syndrome due to a pathological mutation in the mtDNA polymerase gamma. This syndrome causes mtDNA depletion and defective OXPHOS function. She clinically improved [36]. KD has been also applied to two patients with mtDNA point mutation, provoking clinical improvement [37, 38]. However, KD effects on mitochondria were not analyzed in any of these patients. On the other hand, KD has not been used in LHON patients, but LHON patients suffer from RGC loss and, in rodent models of RGC damage, it was shown that KD have a RGC neuroprotective effect, preserving its structure and function, increasing mitochondrial respiration and up-regulating mitochondrial biogenesis [39, 40].

\section{Conclusions}

Mitochondrial biogenesis is a potential therapeutic target for LHON [7, 41], and our results suggest that KD might be effective for heteroplasmic and homoplasmic LHON patients.

\section{Methods}

Cybrids were generated by fusing osteosarcoma 143B cells with mitochondria but no mtDNA, rho ${ }^{0}$ cells, to platelets, with mitochondria and mtDNA but no nucleus or nuclear DNA (nDNA), from three homoplasmic $(\mathrm{m} .3460 \mathrm{G}>\mathrm{A}, \quad \mathrm{m} .11778 \mathrm{G}>\mathrm{A}$ and $\mathrm{m} .14484 \mathrm{~T}>\mathrm{C})$ LHON patients, one heteroplasmic $(\mathrm{m} .13094 \mathrm{~T}>\mathrm{C})$ LHON patient and two control individuals, according to previously described protocols [42]. These cells should share the nDNA and the growing conditions and should differ in their mtDNA genotype. Institutional review boards of all participating centers approved this study (CEICA CP-12/2014). Informed consent was obtained from all subjects.

Growing media were DMEM supplemented with 10 mM HEPES, $4 \mathrm{mM} \mathrm{L-glutamine,} 1 \mathrm{mM}$ sodium pyruvate, $10 \%$ fetal bovine serum (FBS) and $25 \mathrm{mM}$ (high glucoseHG); $5.5 \mathrm{mM}$ (low glucose- LG); or no glucose (NG). In $K D$, fatty acids are used in liver to produce ketone bodies, mainly AA and BHB. Cybrids and fibroblasts were defrosted and grown in HG medium during 3 days and passed to LG medium for another 2 days. Then, we seeded $1 \times 10^{6}$ cells from each cell line in $100 \mathrm{~mm}$-plates with LG medium. Next day, the medium was changed to LG medium plus $50 \mu \mathrm{g} / \mathrm{ml}$ uridine or NG medium plus $50 \mu \mathrm{g} / \mathrm{ml}$ uridine and $5 \mathrm{mM}$ AA and/or $5 \mathrm{mM}$ BHB. Cells were cultured for 7 days, changing the culture medium every second day, and no allowing them to overcome a confluence of $80 \%$. These AA and BHB concentrations were selected in agreement with physiological levels in patients on KD [5]. Cells were kept in $5 \% \mathrm{CO}_{2}$ at $37^{\circ} \mathrm{C}$. 
Total DNA was extracted using a commercial kit. The confirmation of LHON mutations was performed by polymerase chain reaction/restriction fragment length polymorphism (PCR/RFLP), as previously reported [1], by using specific oligonucleotides primers that corresponded to each primary mutation (m.3460G $>$ A/MT-ND1, m.11778G > A/MT-ND4 and m.14484 T > C/MTND6). The percentage of m.13094 $\mathrm{T}>\mathrm{C}$ mutation was also analyzed by PCR/RFLP by using primers $12906 \mathrm{Fw}$ ( $5^{\prime}$-CCTA CACTCCAACTCATGAGACCCA-3') and 13310Rv (5'TGCTAGGTGTGGTTGGTTGATGCCG $-3^{\prime}$ ). The amplicon size is 406 base pairs (bp), and the PCR conditions $95^{\circ} \mathrm{C} 5 \mathrm{~min}\left(95^{\circ} \mathrm{C} 45 \mathrm{~s} / 64^{\circ} \mathrm{C} 30 \mathrm{~s} / 72^{\circ} \mathrm{C} 2 \mathrm{~min}\right) 35$ cycles, $72^{\circ} \mathrm{C} 5 \mathrm{~min}$. The restriction enzyme AluI cuts the mutant sequence in two $218+188 \mathrm{bp}$ fragments [12]. The mutation percentages were obtained with the GelProAnalyzer 4.0 program by scanning bands from RFLP gels. The mtDNA copy number was determined by the qRT-PCR method, as described elsewhere [43]. Briefly, a 123 bp (807 to 929) fragment of mitochondrial 12S RNA gene was analyzed. The primers used to detect the mtDNA $12 \mathrm{~S}$ sequences were MT-L (5'-CCACGGGAAACAGCAGT GATT-3') and MT-H (5'-CTATTGACTTGGGTTAATC GTGTGA-3') and were used together with the mtDNA specific fluorescent-type MGB (minor groove binding) Taqman probe, which was labeled internally by the fluorescent dye FAM (5'-TGCCAGCCACCGCG-3'). Probe and primers designs were implemented with Primer Express 2.0 software. The mtDNA quantity was corrected by simultaneous measurement of a single copy nuclear RNase P gene. To quantify nDNA, a commercial kit was used (PDARs RNAseP), and the nDNA specific fluorescent probe was labeled internally using the fluorescent dye VIC.

ATP amount, normalized by the cell number, was measured following previously described protocols with slight modifications [44], using the CellTiterGlow Luminiscent Cell Viability Assay according to the manufacturer's instructions. Briefly, 10,000 cells/ well were seeded $14-16 \mathrm{~h}$ before measurement. Then, cells were washed twice with PBS and incubated for $2 \mathrm{~h}$ in record solution with $5 \mathrm{mM}$ 2-deoxy-D-glucose plus $1 \mathrm{mM}$ pyruvate (oxidative ATP production). Cells were lysed, and lysates were incubated with the luciferin/luciferase reagents. Samples were measured using a microplate luminometer, and the results referred to cell number.

Data for mean and standard deviation are presented. One-way ANOVA, Bonferroni post-hoc test and t-test were used to compare parameters. $P$-values lower than 0.05 were considered statistically significant.
Authors' contributions

$\mathrm{SE}, \mathrm{EL}-\mathrm{G}, \mathrm{CH}-\mathrm{A}$ and $\mathrm{MH}$ have constructed cybrid cell lines and performed experiments. JM, MPB-B and ER-P designed and supervised this work and wrote the manuscript. All authors read and approved the final manuscript.

\section{Funding}

This work was supported by the Instituto de Salud Carlos III (grant numbers PI17/00021 and PI17/00166); the Gobierno de Aragón (Grupos de Referencia B33_17R) and FEDER 2014-2020 "Construyendo Europa desde Aragón"; and Asociación de Enfermos de Patología Mitocondrial (AEPMI). The CIBERER is an initiative of the ISCIII. Funding bodies have no influenced the design of the study and collection, analysis, and interpretation of data and in writing the manuscript.

\section{Availability of data and materials}

The datasets used and/or analysed during the current study are available from the corresponding author on reasonable request.

\section{Ethics approval and consent to participate}

Not applicable.

\section{Consent for publication}

Not applicable.

\section{Competing interests}

The authors declare that they have no competing interests.

\section{Author details}

'Departamento de Bioquímica, Biología Molecular y Celular, Universidad de Zaragoza, C/ Miguel Servet, 177. 50013, Zaragoza, Spain. ${ }^{2}$ Instituto de Investigación Sanitaria (IIS) de Aragón, Av. San Juan Bosco, 13. 50009 Zaragoza, Spain. ${ }^{3}$ Centro de Investigaciones Biomédicas en Red de Enfermedades Raras (CIBERER), Av. Monforte de Lemos, 3-5. Pabellon 11, Planta 0. 28029, Madrid, Spain. ${ }^{4}$ Fundación ARAID, ARAID, Av. de Ranillas, 1-D. Planta 20, oficina B. 50018, Zaragoza, Spain.

Received: 15 January 2019 Accepted: 11 June 2019

Published online: 21 June 2019

\section{References}

1. Emperador S, Vidal M, Hernandez-Ainsa C, Ruiz-Ruiz C, Woods D, MoralesBecerra A, Arruga J, Artuch R, Lopez-Gallardo E, Bayona-Bafaluy MP, et al. The Decrease in Mitochondrial DNA Mutation Load Parallels Visual Recovery in a Leber Hereditary Optic Neuropathy Patient. Front Neurosci. 2018;12:61.

2. Yu-Wai-Man P, Chinnery PF: Leber Hereditary Optic Neuropathy. 2000 Oct 26 [Updated 2016 Jun 23]. In: Adam MP, Ardinger HH, Pagon RA, et al., editors. GeneReviews ${ }^{T M}$ [internet]. Seattle: University of Washington. 19932018. Available from: http://www.ncbi.n/m.nih.gov/books/NBK1174/.

3. Chinnery PF, Andrews RM, Turnbull DM, Howell NN. Leber hereditary optic neuropathy: Does heteroplasmy influence the inheritance and expression of the G11778A mitochondrial DNA mutation? Am J Med Genet. 2001;98(3): 235-43.

4. Leo-Kottler B, Jacobi F, Christ-Adler M. Leber optic neuropathy with clinical improvement. Ophthalmologe. 2000;97(12):849-54.

5. Santra S, Gilkerson RW, Davidson M, Schon EA. Ketogenic treatment reduces deleted mitochondrial DNAs in cultured human cells. Ann Neurol. 2004; 56(5):662-9.

6. Bianco A, Martinez-Romero I, Bisceglia L, D'Agruma L, Favia P, Ruiz-Pesini E, Guerriero S, Montoya J, Petruzzella V. Mitochondrial DNA copy number differentiates the Leber's hereditary optic neuropathy affected individuals from the unaffected mutation carriers. Brain. 2016;139(Pt 1):e1.

7. Ruiz-Pesini E, Emperador S, Lopez-Gallardo E, Hernandez-Ainsa C, Montoya J. Increasing mtDNA levels as therapy for mitochondrial optic neuropathies. Drug Discov Today. 2018;33(3):493-8.

8. Frey S, Geffroy G, Desquiret-Dumas V, Gueguen N, Bris C, Belal S, AmatiBonneau P, Chevrollier A, Barth M, Henrion D, et al. The addition of ketone bodies alleviates mitochondrial dysfunction by restoring complex I assembly in a MELAS cellular model. Biochim Biophys Acta. 2017;1863(1): 284-91.

9. Karanjia R, Chahal J, Ammar M, Sadun AA. Treatment of Leber's Hereditary Optic Neuropathy. Curr Pharm Des. 2017;23(4):624-8. 
10. Lopez-Gallardo E, Emperador S, Hernandez-Ainsa C, Montoya J, BayonaBafaluy MP, Ruiz-Pesini E. Food derived respiratory complex I inhibitors modify the effect of Leber hereditary optic neuropathy mutations. Food Chem Toxicol. 2018;120:89-97.

11. Gomez-Duran A, Pacheu-Grau D, Martinez-Romero I, Lopez-Gallardo E, Lopez-Perez MJ, Montoya J, Ruiz-Pesini E. Oxidative phosphorylation differences between mitochondrial DNA haplogroups modify the risk of Leber's hereditary optic neuropathy. Biochim Biophys Acta. 2012;1822(8): 1216-22.

12. Valente L, Piga D, Lamantea E, Carrara F, Uziel G, Cudia P, Zani A, Farina L, Morandi L, Mora M, et al. Identification of novel mutations in five patients with mitochondrial encephalomyopathy. Biochim Biophys Acta. 2009; 1787(5):491-501.

13. Desquiret-Dumas V, Gueguen N, Barth M, Chevrollier A, Hancock S, Wallace DC, Amati-Bonneau P, Henrion D, Bonneau D, Reynier P, et al. Metabolically induced heteroplasmy shifting and I-arginine treatment reduce the energetic defect in a neuronal-like model of MELAS. Biochim Biophys Acta. 2012;1822(6):1019-29.

14. Newman JC, Verdin E. Ketone bodies as signaling metabolites. Trends Endocrinol Metab. 2014;25(1):42-52.

15. Robinson BH, Petrova-Benedict R, Buncic JR, Wallace DC. Nonviability of cells with oxidative defects in galactose medium: a screening test for affected patient fibroblasts. Biochem Med Metab Biol. 1992:48(2):122-6.

16. Reitzer $L$, Wice BM, Kennell $D$. Evidence that glutamine, not sugar, is the major energy source for cultured HeLa cells. J Biol Chem. 1979;254(8):2669-76.

17. Rossignol R, Gilkerson R, Aggeler R, Yamagata K, Remington SJ, Capaldi RA. Energy substrate modulates mitochondrial structure and oxidative capacity in cancer cells. Cancer Res. 2004;64(3):985-93.

18. Balsa E, Soustek MS, Thomas A, Cogliati S, Garcia-Poyatos C, Martin-Garcia E, Jedrychowski M, Gygi SP, Enriquez JA, Puigserver P. ER and Nutrient Stress Promote Assembly of Respiratory Chain Supercomplexes through the PERKelF2alpha Axis. Mol Cell. 2019.

19. Giordano C, Montopoli M, Perli E, Orlandi M, Fantin M, Ross-Cisneros FN, Caparrotta L, Martinuzzi A, Ragazzi E, Ghelli A et al: Oestrogens ameliorate mitochondrial dysfunction in Leber's hereditary optic neuropathy. Brain 2011, 134(Pt 1):220-234.

20. Palmeira CM, Rolo AP, Berthiaume J, Bjork JA, Wallace KB. Hyperglycemia decreases mitochondrial function: the regulatory role of mitochondrial biogenesis. Toxicol Appl Pharmacol. 2007;225(2):214-20.

21. Geffroy G, Benyahia R, Frey S, Desquiret-Dumas V, Guequen N, Bris C, Belal S, Inisan A, Renaud A, Chevrollier A, et al. The accumulation of assembly intermediates of the mitochondrial complex I matrix arm is reduced by limiting glucose uptake in a neuronal-like model of MELAS syndrome. Biochim Biophys Acta Mol Basis Dis. 2018;1864(5 Pt A):1596-608.

22. Weber K, Ridderskamp D, Alfert M, Hoyer S, Wiesner RJ. Cultivation in glucose-deprived medium stimulates mitochondrial biogenesis and oxidative metabolism in HepG2 hepatoma cells. Biol Chem. 2002;383(2): 283-90.

23. Bough KJ, Wetherington J, Hassel B, Pare JF, Gawryluk JW, Greene JG, Shaw R, Smith Y, Geiger JD, Dingledine RJ. Mitochondrial biogenesis in the anticonvulsant mechanism of the ketogenic diet. Ann Neurol. 2006;60(2): 223-35

24. Al-Zaid NS, Dashti HM, Mathew TC, Juggi JS. Low carbohydrate ketogenic diet enhances cardiac tolerance to global ischaemia. Acta Cardiol. 2007; 62(4):381-9.

25. Nylen K, Velazquez JL, Sayed V, Gibson KM, Burnham WM, Snead OC 3rd. The effects of a ketogenic diet on ATP concentrations and the number of hippocampal mitochondria in Aldh5a1(-/-) mice. Biochim Biophys Acta. 2009;1790(3):208-12.

26. Martinez-Outschoorn UE, Lin Z, Whitaker-Menezes D, Howell A, Lisanti MP, Sotgia F. Ketone bodies and two-compartment tumor metabolism: stroma ketone production fuels mitochondrial biogenesis in epithelial cancer cells. Cell Cycle. 2012;11(21):3956-63.

27. Srivastava S, Kashiwaya Y, King MT, Baxa U, Tam J, Niu G, Chen X, Clarke K, Veech RL. Mitochondrial biogenesis and increased uncoupling protein 1 in brown adipose tissue of mice fed a ketone ester diet. FASEB J. 2012;26(6): 2351-62.

28. Hasan-Olive MM, Lauritzen KH, Ali M, Rasmussen LJ, Storm-Mathisen J, Bergersen LH. A Ketogenic Diet Improves Mitochondrial Biogenesis and Bioenergetics via the PGC1alpha-SIRT3-UCP2 Axis. Neurochem Res. 2019; 44(1):22-37.
29. Garcia-Roves P, Huss JM, Han DH, Hancock CR, Iglesias-Gutierrez E, Chen M, Holloszy JO. Raising plasma fatty acid concentration induces increased biogenesis of mitochondria in skeletal muscle. Proc Natl Acad Sci U S A. 2007;104(25):10709-10,713.

30. Ahola-Erkkila S, Carroll CJ, Peltola-Mjosund K, Tulkki V, Mattila I, SeppanenLaakso T, Oresic M, Tyynismaa H, Suomalainen A. Ketogenic diet slows down mitochondrial myopathy progression in mice. Hum Mol Genet. 2010; 19(10):1974-84.

31. Lauritzen KH, Hasan-Olive MM, Regnell CE, Kleppa L, Scheibye-Knudsen M, Gjedde A, Klungland A, Bohr VA, Storm-Mathisen J, Bergersen LH. A ketogenic diet accelerates neurodegeneration in mice with induced mitochondrial DNA toxicity in the forebrain. Neurobiol Aging. 2016;48:34-47.

32. Li Y, Li HZ, Hu P, Deng J, Banoei MM, Sharma LK, Bai Y. Generation and bioenergetic analysis of cybrids containing mitochondrial DNA from mouse skeletal muscle during aging. Nucleic Acids Res. 2010;38(6):1913-21.

33. Zhou H, Nie K, Qiu R, Xiong J, Shao X, Wang B, Shen L, Lyu J, Fang H. Generation and Bioenergetic Profiles of Cybrids with East Asian mtDNA Haplogroups. Oxid Med Cell Longev. 2017;2017:1062314.

34. Nishioka T, Soemantri A, Ishida T. mtDNA/nDNA ratio in 14,484 LHON mitochondrial mutation carriers. J Hum Genet. 2004;49(12):701-5.

35. Kang HC, Lee YM, Kim HD, Lee JS, Slama A. Safe and effective use of the ketogenic diet in children with epilepsy and mitochondrial respiratory chain complex defects. Epilepsia. 2007;48(1):82-8.

36. Joshi CN, Greenberg CR, Mhanni AA, Salman MS. Ketogenic diet in AlpersHuttenlocher syndrome. Pediatr Neurol. 2009;40(4):314-6.

37. Buda P, Piekutowska-Abramczuk D, Karkucinska-Wieckowska A, Jurkiewicz E, Chelstowska S, Pajdowska M, Migdal M, Ksiazyk J, Kotulska K, Pronicka E. "Drop attacks" as first clinical symptoms in a child carrying MTTK m.8344A > G mutation. Folia Neuropathol. 2013;51(4):347-54.

38. Steriade C, Andrade DM, Faghfoury H, Tarnopolsky MA, Tai P. Mitochondrial encephalopathy with lactic acidosis and stroke-like episodes (MELAS) may respond to adjunctive ketogenic diet. Pediatr Neurol. 2014;50(5):498-502.

39. Zarnowski T, Choragiewicz TJ, Schuettauf F, Zrenner E, Rejdak R, Gasior M, Zarnowska I, Thaler S. Ketogenic diet attenuates NMDA-induced damage to rat's retinal ganglion cells in an age-dependent manner. Ophthalmic Res. 2015;53(3):162-7.

40. Harun-Or-Rashid M, Pappenhagen N, Palmer PG, Smith MA, Gevorgyan V Wilson GN, Crish SD, Inman DM. Structural and Functional Rescue of Chronic Metabolically Stressed Optic Nerves through Respiration. J Neurosci. 2018;38(22):5122-39.

41. Storoni M, Robert MP, Plant GT. The therapeutic potential of a calorierestricted ketogenic diet for the management of Leber hereditary optic neuropathy. Nutr Neurosci. 2017:1-9.

42. Chomyn A. Platelet-mediated transformation of human mitochondrial DNAless cells. Methods Enzymol. 1996;264:334-9.

43. Marcuello A, Gonzalez-Alonso J, Calbet JA, Damsgaard R, Lopez-Perez MJ, Diez-Sanchez C. Skeletal muscle mitochondrial DNA content in exercising humans. J Appl Physiol (1985). 2005;99(4):1372-7.

44. Gomez-Duran A, Pacheu-Grau D, Lopez-Gallardo E, Diez-Sanchez C, Montoya J, Lopez-Perez MJ, Ruiz-Pesini E. Unmasking the causes of multifactorial disorders: OXPHOS differences between mitochondrial haplogroups. Hum Mol Genet. 2010;19(17):3343-53.

\section{Publisher's Note}

Springer Nature remains neutral with regard to jurisdictional claims in published maps and institutional affiliations.

Ready to submit your research? Choose BMC and benefit from:

- fast, convenient online submission

- thorough peer review by experienced researchers in your field

- rapid publication on acceptance

- support for research data, including large and complex data types

- gold Open Access which fosters wider collaboration and increased citations

- maximum visibility for your research: over $100 \mathrm{M}$ website views per year

At $\mathrm{BMC}$, research is always in progress.

Learn more biomedcentral.com/submission 